\title{
Lugar Ampliado, Espaço e Poder
}

Igor José de Renó Machado Procurarei aqui entender a importância da movimentação de pessoas para Estação Passos $^{1}$, um distrito do município de São J oão, sul de Minas Gerais ${ }^{2}$. A intenção é demonstrar como a movimentação transforma a realidade local, usando como exemplo a construção de um modelo de vida compartilhado que estabelece novos critérios para as disputas políticas locais. O foco do artigo é a construção de categorias nativas de inclusão e exclusão e as conseqüências deste processo na elaboração de categorias de tempo e espaço. O pequeno distrito de Passos, como é conhecido, é encarado em sua principal característica: a extrema movimentação das pessoas, que representa um leque múltiplo de possibilidades, desde migrações definitivas até aquelas diárias, típicas de uma 'comunidade-dormitório'. Esta característica é fundamental para o entendimento do universo simbólico local e constitui a linguagem das relações de poder e também se relaciona com novas formas de construção do tempo e espaço ${ }^{3}$.

A movimentação, enquanto um fenômeno em si, é a qualificadora de capitais sociais (Bourdieu 1989). A circulação das pessoas em torno de um lugar geográfico específico, a própria Passos, legitima a dominação de alguns sobre os demais e fornece a linguagem simbólica através da qual se configuram vários fenômenos locais. Essa movimentação é pensada também como um universo simbólico que estabelece diferenças sociais e de status entre os habitantes locais. Esse talvez seja um fenômeno comum a vários municípios brasileiros, nos quais pessoas em movimento, pelos mais variados motivos, constróem bases para a dominação política.

Procurarei demonstrar como o fluxo de pessoas qualifica status pessoais dentro de um espaço geográfico delimitado, como a movimentação constitui a arena

Campos 2:101-115, 2002. local de poder. O entendimento dessa como um fenômeno social acarretou também 
a análise de mudanças nas noções de tempo e espaço. Esse estudo é fruto da pesquisa para a dissertação de mestrado, defendida em agosto de 1997, e centrou-se numa localidade geográfica e numa outra simbólica, construída a partir da movimentação das pessoas e de seus trajetos fora do distrito (o que chamei de lugar ampliado). Primeiramente, apresentarei a importância da movimentação, para em seguida demonstrar como é fundamental para entendermos as percepções de espaço e tempo.

\section{HISTÓRICO}

O bairro se formou gradualmente a partir da instalação de uma estação de trem. A região, que já era razoavelmente habitada enquanto área rural, passou a ter um caráter de entreposto numa linha que ia de Itareno a São J oão. Portanto, a vila já nasce em torno de uma idéia de movimentação entre cidades, de deslocamento. O que considero 'lugar ampliado' começa a surgir com a sua criação. Mesmo quando a linha foi desativada, por volta de 1960, a rodovia já estava pronta e, como seguia paralelamente à linha de trem, é paralela à vila.

A história política do distrito foi marcada pela mudança crucial da forma do poder que, de "coronelista"4, passa a ser disputado numa arena pública dominada por mulheres líderes no distrito. Denomino essa 'ocupação' de "feminilização da esfera política" , através da qual o cenário político mudou radicalmente ao longo do tempo. Esse processo foi concomitante à história da falência econômica do distrito, no começo dos anos 80 . Entretanto, trato aqui não do processo de ocupação feminina da esfera da política local, mas da transformação na estrutura desta arena política. Se antes o poder local era mediado pelo poder de um coronel local (que tinha uma expressão reduzida no cenário estadual, mas relevante no cenário municipal), passa, depois da crise do café do começo da década de oitenta (atividade que sustentava a política coronelística local), a ser disputada em outros termos.

Mas até 1980 predominava no distrito o cultivo do café, que ainda trazia bons resultados. A 'elite' era composta pelos plantadores de café e pelo grande comprador e dono da máquina de beneficiamento, Carlos Ribeiro de Lino ${ }^{6}$, visto como o coronel do distrito. Era um homem de bastante influência política, que comandava a economia local como o maior comprador de café do município. Como a sua máquina de beneficiamento estava em Passos, o distrito vivia uma realidade econômica bem mais dinâmica do que hoje em dia. Mas o café entrou em crise e, com ela, a situação de Carlos Ribeiro de Lino mudou. Por volta de 1980, após grandes empréstimos realizados, uma grande geada acabou com a colheita, com a esperança e a saúde financeira de todos os cafeicultores do local. Carlos faliu nessa oportunidade e veio a falecer três anos após, desestruturando a organização política local, antes estabelecida em torno de sua influência e atuação ${ }^{7}$. 
Passos deixou de ser produtora de riquezas: de produtora de café passa a ser uma 'comunidade-dormitório', passando por um 'achatamento' de sua importância econômica para o município como um todo. Enquanto vivo, Carlos Ribeiro de Lino fez o papel do principal intermediador entre o local e as elites estaduais no município. Com sua falência e morte, o conseqüente achatamento econômico também foi um achatamento político, pois o 'substituto' de Carlos como intermediador político no município não tinha bases políticas em Passos. A transformação da forma de poder se deu nesse contexto, quando o cenário político em Passos foi repentinamente 'esvaziado'. O argumento principal deste artigo foi elaborado a partir da análise da reconstrução desse espaço político.

Com a morte de Carlos, metáfora e metonímia da falência política e econômica de Passos, transformou-se a economia local, e transformou-se o universo simbólico. Com a mudança econômica, aumentou enormemente a movimentação constante entre as cidades. Passos passou a ser exportadora de trabalhadores para as cidades locais. Gradualmente, através de um processo histórico (Sahlins 1990), o universo simbólico passou a ser elaborado a partir do fenômeno da movimentação, que veio a ser o nexo das disputas políticas. Esses processos, a falência econômica, a movimentação e a mudança da vida política, em conjunto, causaram uma mudança sensível nas relações sociais locais, principalmente no que se refere às relações de gênero. Afinal, se antes a esfera política era o próprio Carlos, posteriormente foi ocupada por um núcleo atuante de mulheres, o que acarretou modificações nos papéis relativos ao gênero (cf. Machado 1997).

\section{MOVIMENTAÇÃO}

Mas entendamos, de vez, como defino movimentação. Esta ocorre em dois níveis: um deles é o que vou chamar de movimentação regional mais ou menos duradoura e, outro, o da movimentação local 'instantânea', abreviadas aqui como regional e local. A primeira consiste de um movimento bastante comum às cidades do sul de Minas nas décadas de 60 e 70. Corresponde a uma 'onda' de migração interna, que levou grande parte das pessoas desses municípios para grandes centros próximos à região, em busca de melhores empregos, salários e condições de vida. Nas décadas de 60 e 70, com o crescimento da indústria no Brasil, e com o grande parque industrial de São J osé dos Campos em franca expansão, as condições de absorção de mão-de-obra não-qualificada eram bastante significativas. As oportunidades no comércio e no setor terciário em geral também eram favoráveis. Assim, através de redes de parentesco que existem em profusão em São J oão, um grande contigente de pessoas para lá se mudou.

Essa movimentação regional implica deixar o município de origem, mas não perder o elo de ligação, pois a 
facilidade e a proximidade fazem com que as pessoas sempre visitem a cidade de origem. A relação com o município de origem continua muito forte, e as famílias criam redes por onde passam seus membros, mantendo os laços existentes. Essa movimentação familiar causa uma inevitável ligação com o município de origem, mesmo para as gerações que já nasceram nas cidades industriais, pois sempre se visita a cidade dos pais, passam-se férias, fazem-se amigos etc. Os que saíram continuam a se socializar nas cidades de origem ${ }^{8}$ Em vários casos, os migrantes voltam para as cidades de onde saíram após terem se aposentado.

Assim, essa movimentação regional geralmente não tem um caráter definitivo. Ela obedece a movimentos da economia nacional, aumentando nos períodos de expansão da economia e se retraindo em períodos de crise. À época da pesquisa, 1997, a situação apresentava duas faces: a evidente retração da economia e o aumento do desemprego anteciparam a volta de muitos migrantes que haviam partido para os grande centros; mas, por outro lado, a existência das sólidas redes familiares continuava a levar outros migrantes para essas cidades, que em geral conseguiam empregos através de parentes em melhores condições econômicas.

A outra movimentação, abreviada como local, não implica um abandono do local de moradia, no caso, do distrito de origem; consiste em movimentar-se constantemente entre as cidades próximas, ou para trabalho, ou para estudo, ou ainda para fazer compras, ir ao médico, em busca de lazer etc. Implica sempre um retorno à moradia de origem no final de algum tempo, que pode ser o mesmo dia ou até uma semana. É uma movimentação rápida e fácil, devido aos meios de locomoção, e constante, devido ao seu caráter. Ou seja, uma movimentação característica de uma comunidade-dormitório.

Estamos, dessa forma, em meio a uma constante movimentação das pessoas entre as cidades vizinhas. Muitos dos habitantes trabalham em São J oão e moram em Passos, outros trabalham em Itareno. Outros tentaram a sorte em outras cidades, desistiram e voltaram; outros ainda foram viver em cidades diversas e depois de muito tempo voltaram, já aposentados, para morar em Passos. Mesmo quem nunca saiu de fato está sempre deslocandose a essas cidades para fazer compras, divertir-se etc (é bom lembrar que Passos fica na beira da rodovia que liga o sul de Minas a São J osé dos Campos). A educação das crianças étambém outro estimulador dessa movimentação extrema, pois a vila conta apenas com uma escola de nível primário, forçando as crianças e jovens a estudarem em São J oão (muitos fazem o curso técnico em eletrônica). Passos é marcada por essa característica movimentação das pessoas, que resulta na comparação com outros lugares e numa eterna divisão entre Passos e o 'mundo'.

Esta movimentação viveu ritmos diferentes e tendeu a diminuir quando o distrito foi capaz de gerar as próprias riquezas, através do café. No entanto, ela nunca deixou de estar presente, de uma forma ou de outra. $O$ importante é ressaltar que essa movimentação aumentou consideravelmente a partir dos anos oitenta, devido à 104 crise econômica: alternativas tiveram que ser buscadas fora de Passos, acentuando a necessidade de movimentação. 
Muitos deixaram o distrito, outros fazem dele uma 'comunidade-dormitório'. Essa situação em muito alterou a rotina dos habitantes, levados a se acostumar com outro ritmo de vida. Além disso, a própria concepção de poder mudou drasticamente: não existia mais o coronel Carlos Ribeiro de Lino, nem sua base político-econômica; não havia mesmo condições para que fosse substituído por algum parente. As condições mudaram, a situação se transformou, influenciando também uma mudança na forma de buscar o poder.

Essas pessoas que fazem de Passos uma 'comunidade-dormitório' representam um número relativamente alto, constituindo uma certa 'elite' dentro do bairro, pois têm acesso a outras informações, a outros lugares e não dependem da agricultura para sobreviver. Com um salário regular no fim do mês, têm garantida uma estabilidade econômica razoável, diferentemente dos agricultores que dependem muito de circunstâncias variadas, que no momento da pesquisa eram péssimas. Essas condições vão desde o clima até políticas econômicas que, como se sabe, são tenebrosas para esses pequenos agricultores, pois estando completamente alijados do sistema bancário, não têm como conseguir qualquer tipo de empréstimo.

As pessoas que trabalham fora têm diferentes ocupações: algumas estudaram e fizeram o curso superior, enquanto outras têm negócios variados, trabalhando como radialistas, taxistas, caminhoneiros, vendedores, professoras etc. Esses 'movimentantes' compõem a elite local não apenas pela maior segurança econômica, mas também pelo fato de ocuparem um lugar ampliado e fazerem disso uma legitimação para o papel político. Utilizam sistematicamente um discurso que envolve algumas palavras 'nativas' fundamentais, ligadas às suas vidas de movimentação intensa e que têm um valor muito acentuado na vida cotidiana: "vivência" (que no caso quer dizer vivência unicamente da experiência de movimentação), "cabeça aberta" (só quem sai de Passos pode raciocinar mais profundamente sobre a sua situação e pode achar respostas para seus problemas). Essa expressão também revela uma discriminação contra os que não saíram de Passos, chamados de "gente pequena", ignorantes, fechados às mudanças e preconceituosos. Para essa elite, "inteligente" é quem viveu essa experiência de movimentação, em oposição aos que permaneceram sempre na vila e não ampliaram os horizontes.

Com esses termos se constrói, por parte dos que saíram ou saem constantemente de Passos, um discurso valorizando essa movimentação como algo estruturalmente diferenciador dos moradores, elaborando limites entre dois grupos separados, numa estrutura binária: de um lado, as "trevas"9 (não movimentação, ignorância, falta de estudo, trabalho manual); de outro, as "luzes" (quem conhece outros lugares, é esclarecido, cabeça aberta, não preconceituoso etc.). Dessa maneira, construiu-se uma rede, estabelecendo uma elite política e econômica que justifica suas ações e aspirações com esse discurso. Mas é preciso ressaltar que, se essa 'elite' tem uma vantagem econômica sobre os demais, ela é bem menos acentuada do que pensamos quando falamos em 'elite'; às vezes ela nem se concretiza de fato, e o discurso da movimentação é usado para criar uma diferenciação e delimitar 
diferenças 'culturais' onde não existem muitas distinções econômicas. O fato é que a partir dessa noção de movimentação (e não-movimentação) se estabelece uma divisão social muito clara, o que afetará diretamente os processos políticos. Portanto, lembremos que essas distinções constróem discursos de exclusão muito fáceis de serem percebidos e observados.

\section{MOVIMENTAÇÃO E RELAÇÕES DE PODER}

A movimentação se baseia, antes de tudo, num modo de vida específico que é construído no tempo, que pode ser atingido em maior ou menor grau segundo os ritmos específicos de vida de cada um. Podem mesmo não ser cumpridos de forma alguma, o que implica um isolamento da vida política do lugar. Quanto mais próximas do padrão ideal de vida, mais respeitadas se tornam as pessoas dentro desse contexto. No entanto, devo salientar que essa movimentação é fruto da ação de determinados núcleos de pessoas, que legitimam sua influência a partir de um discurso de inclusão e exclusão, na medida em que vivenciam esse modelo de vida. Assim, quem não participa desse modo específico de vida é o 'outro', visto como ignorante, atrasado e incapaz de perceber as qualidades do 'nós'.

A movimentação conduz ao que poderíamos chamar de uma 'percepção ampliada do lugar', que é a construção simbólica do distrito numa dimensão maior que sua própria existência física. O distrito é imaginado como um espaço maior que suas três ruas paralelas, um espaço ampliado onde se encontram vários pedaços do 'lugar' que fazem parte do distrito, mas que não estão na sua estrutura física. O distrito-vila acaba por ser maior que a sua dimensão territorial, inclui os espaços pelos quais seus membros costumam passar, além dos espaços pelos quais eles ainda vão passar. Assim, a passagem por essa ampliação da cidade (pelos seus espaços fora dela mesma) é também uma legitimação do papel de alguns membros na comunidade. Quando passam pelos lugares habituais da vila em outras cidades (como as escolas, os mercados, trabalhos fixos etc.), tornam-se mais 'completos', pois todos deveriam passar por esse papel. Os que o cumprem de maneira mais completa são mais 'legítimos', têm mais influência política sobre os membros locais e maiores qualificações para enfrentar as disputas políticas no interior da vila.

O lugar ampliado é fundamental em termos econômicos, pois a maioria das pessoas tem empregos fora da vila, ou precisam deixá-la para vender a produção em feiras de cidades locais. De forma geral, a aquisição do dinheiro é, hoje em dia, sempre ligada às cidades em volta de Passos, assim como a educação formal das crianças e jovens. Grande parte dos jovens estudam segundo as opções encontradas nas cidades vizinhas. Em São J oão se 
encontra um curso técnico em eletrônica que oferece um curso noturno, muito freqüentado pelos alunos passenses. Em Itareno, encontram-se algumas faculdades, que são, em menor proporção, os caminhos de alguns estudantes que conseguem terminar o segundo grau. Mas mesmos os trabal hadores rurais (que têm que vender sua produção nessas cidades), tentam se apropriar desse lugar ampliado. A maioria tem na própria história uma tentativa, em geral frustrada, de se fixar em alguma cidade. Entre as pessoas que entrevistei, várias tinham uma história de deslocamento para "melhorar a vida". Mas mesmo essa passagem rápida pela cidade é valorizada como uma aproximação ao ideal da movimentação. Mas é preciso qualificar que as movimentações são diferenciadas entre si, com diferentes escalas de valores relacionadas. As movimentações de jovens em busca de diversão não têm o mesmo valor que as dos que trabalham fora do bairro, por exemplo. Entretanto, qualquer movimentação é melhor que nenhuma movimentação.

A movimentação é baseada e ao mesmo tempo criadora desse lugar ampliado, permitindo ou levando a um acúmulo de capital cultural determinante para a qualificação do capital social (Bourdieu 1977, 1983, 1989) dos indivíduos. Quem se movimenta mais adquire mais capital cultural, o que leva a um maior capital social. A movimentação em si traz para os indivíduos mais conhecimentos ou, nas palavras nativas, mais vivência. Essa vivência é um acúmulo de experiências oferecidas pela passagem por diferentes lugares, pelo contato com pessoas diferentes e também por possibilitar um maior capital econômico. A vivência é a base da distinção entre os classificados como gente pequena e os demais que se movimentam, legitimando a dominação destes sobre os primeiros. Em contraposição com a agricultura da gente pequena, o capital cultural acumulado dos que têm vivência está também ligado ao capital econômico que os trabalhos fora de Passos oferecem.

De fato, quem trabalha fora tem mais dinheiro. No entanto, a relação entre esse capital econômico e o cultural não é necessária, pois o que importa é o quantum de capital cultural acumulado. O capital econômico permite, sim, um maior quantum de capital cultural, pois com mais dinheiro mais se movimenta, mais se tem vivência. Com um emprego fixo em outra cidade, a movimentação é compulsória e constante, e não ocasional, como no caso da gente pequena. Permite mais vivência, mas não é a única forma de adquiri-la. Assim, o desenvolvimento histórico da movimentação, bem como o universo simbólico dela resultante, influem na vida de todos, mesmo nas da gente pequena. Estes últimos reconhecem nessa movimentação o principal capital cultural da vida local, legitimando a própria dominação a que são submetidos, pois acreditam que é preciso ter vivência para ser alguém. É por isso que tentam viver algum tipo de movimentação, ou participando de feiras nas cidades vizinhas, ou tentando arranjar trabalho fora de Passos, para também adquirirem capital cultural. Todos, por exemplo, incentivam a educação dos filhos em cidades vizinhas, o que já lhes confere um status diferente.

Portanto, para entender as disputas internas por poder é preciso ter em mente que a movimentação supõe 
um modelo ideal de cidadão a ser atingido e a disputa política é influenciada por esse modelo, legitimando algumas pessoas mais do que outras. Nesse sentido, estudar as trajetórias das pessoas por entre as cidades e entender seus deslocamentos é fundamental para entendermos Passos. Como demonstrou J oan Vincent (1987), a análise do fluxo das pessoas (no seu caso, das pessoas da sociedade agrária), do papel das mulheres, rapazes e crianças, é fundamental para o entendimento de situações sociais.

O modelo ideal de vida, paradoxalmente, é aquele em que o indivíduo sai completamente do cotidiano da vila, perdendo os laços mais íntimos com a 'comunidade'. Assim, se um indivíduo estuda fora, consegue emprego numa cidade distante e se insere em outras comunidades, cumpriu o modelo ideal e desfruta de um grande prestígio. Mas também está alijado das disputas políticas internas, pois essas não fazem mais sentido no seu cotidiano. O que acontece é que a disputa política é realizada por aqueles que não 'completaram' ainda o modelo ideal, uma disputa de 'imperfeitos', disputando a maior legitimidade de sua posição em função dos adversários. Dessa forma, estamos num terreno marginal onde são construídos discursos de legitimação não necessariamente reais, mas que servem como elementos nas disputas políticas; pessoas tentam aproximar-se do modelo através da construção de argumentos, nem sempre verídicos. O problema é que alguns têm mais condições de chegar perto desse modelo, de se movimentar mais e de obter maior capital cultural do que outros. Essa condição estabelece a dominação de uns sobre os demais.

A movimentação é, assim, uma opção que depende de vários fatores. Porém, em termos de disputa política, era a única via que se apresentava. Mas lembremos que não foi assim num passado não muito distante, pois antes o poder era executado de forma 'coronelista' por Carlos Ribeiro de Lino. No presente, entretanto, a disputa é toda entre pessoas que passaram por essa vivência em maior ou menor grau, ou ainda que a legitimam de alguma forma, mesmo admitindo que normas e padrões alternativos podem se confrontar na ação dos indivíduos - como pondera Van Velsen (1987). Porém, na disputa política em Passos a movimentação é fundamental e decisiva. A disputa se dá através dos pressupostos da movimentação.

Estas disputas políticas locais são referentes à vida cotidiana do bairro: desde as decisões sobre o que fazer com a sede social disponibilizada pela igreja, sobre quais festas serão realizadas, sobre como melhorar a escola primária local, até as decisões político-partidárias, como a escolha de um candidato a vereador a ser apoiado, a escolha de comissões para negociar melhoramentos na estrutura do bairro com a prefeitura etc. Estas decisões são tomadas por pessoas que atingem melhor o modelo ideal de pessoa com "vivência", decisões que são tomadas por uma minoria (no caso de Passos, uma minoria composta quase exclusivamente por mulheres), autorizada pela legitimação social do papel que desempenham. Não trataremos aqui do detalhe destas disputas, mas vale ressaltar que elas são executadas pelos que se movimentam, excluindo sistematicamente a maioria da população de Passos ${ }^{10}$. 


\section{COMO A MOVIMENTAÇÃO INFLUENCIA AS NOÇÕES DE TEMPO E ESPAÇO}

Como diz Harvey (1994), tempo e espaço não podem ser compreendidos independentemente da ação social e a hegemonia política e ideológica depende de um controle do tempo e do espaço: "As práticas temporais e espaciais nunca são neutras nos assuntos sociais, elas sempre exprimem algum tipo de conteúdo de classe ou conteúdo social, sendo muitas vezes o foco de uma intensa luta social" (idem:218). Porém, as disputas em Passos ocorrem em torno da legitimação de trajetórias pessoais em função de um conceito (não questionado) de espaço e tempo. Com isso não quero dizer que a movimentação é um dado, ou que se manterá assim através dos tempos. Ela é fruto de uma situação sócio-histórica peculiar e através dela se dão disputas sociais. Porém, não é questionada enquanto definição de espaço (e de tempo ${ }^{11}$, por extensão) pelos grupos em disputa, como veremos aqui. Claro, o motivo é que quem disputa compartilha dessa mesma noção de espaço, constituindo uma certa 'elite' local. Retornamos ao discurso de exclusão, que diferencia essa suposta 'elite' do resto da população de Passos. O consenso em torno da noção do 'lugar ampliado', constituinte e constituído pela movimentação, impõe-se através da ação política cotidiana dessas pessoas, e da discriminação que compartilham pelos que não o vivem. Criadora do lugar ampliado, a movimentação passa a ser coletivamente aceita como o capital cultural por excelência, legitimador das diferenças sociais no distrito, e aceito por todos enquanto tal, mesmo os dominados.

Se essa noção de espaço não é questionada no momento, pode vir a sê-lo em algum outro. Por exemplo, a própria disputa interna entre grupos pode ocasionar uma transformação desse pressuposto. Por outro lado, mudanças regionais ou nacionais podem implicar uma percepção modificada de tempos e espaços (como a intensa compressão do tempo/espaço nas últimas décadas, como defende Harvey), podendo também afetar as percepções vigentes. Harvey (1994:218) nos diz que "parte da insegurança que assola o capitalismo como formação social vem dessa instabilidade das movimentações espaciais e temporais em torno das quais a vida social poderia ser organizada (quando não ritualizada à feição das sociedades tradicionais)". O que a movimentação demonstra, entretanto, é que é possível se desenvolverem 'bolsões temporais' de estabilidade da percepção tempo/espaço, mesmo nessa situação de instabilidade descrita por Harvey. A percepção ampliada do lugar inclui, na sua dinâmica, a mudança constante dos espaços no tempo (o espaço de circulação) a partir de um lugar (que é o próprio distrito) demarcado socialmente como qualquer outro lugar.

Assim, se a questão é como representar o tempo diante da fragmentação do espaço (como foi para os modernistas no começo do século), em Passos a abstração do espaço faz parte da vida das pessoas como uma meta a percorrer em busca de legitimação política (claro que não são todas as pessoas que estão interessadas numa disputa política, mas quase todas percorrem esse caminho como o único possível). Se "as qualidades do 
lugar passam a ser enfatizadas em meio às crescentes abstrações do espaço" (Harvey 1994:266), no caso de Passos são essas abstrações do espaço que acabam por ser fundamentais na definição dessa localidade, ou seja, as qualidades do lugar não são enfatizadas em oposição às abstrações espaciais, mas definidas por elas. A transição por vários espaços diferentes, a experiência de diferentes ritmos de tempo, tudo é um modelo ideal (que pode ou não ser executado) para a vida das pessoas do distrito, e é a peça-chave no entendimento das disputas políticas. A fragmentação do espaço faz parte da disputa política na localidade, ritualizando "instabilidades" (como as chama Harvey) na percepção tempo-espaço. Aspectos que marcariam uma instabilidade podem ser normalizados, passando a ser um modo muito estável de percepção do tempo/espaço. Em outras palavras, a própria percepção fragmentada de tempo-espaço pode ser ritualizada ("à feição das sociedades tradicionais") e se tornar norma.

Essa situação 'especial' do distrito está ligada a sua história, muito recente (afinal eu a encaro como algo construído e historicizado, resultado de características específicas dentro de um contexto histórico abrangente e que pode, inclusive, mudar diante de novas conjunturas). O distrito se formou, como vimos, gradualmente a partir da instalação da Estação de trem em 1910. A região já era razoavelmente habitada, enquanto uma zona rural, e passou a ter um caráter de entreposto numa linha que ligava duas cidades. Portanto, Passos ${ }^{12}$ já nasce em torno de uma idéia de movimentação entre cidades, de deslocamento. O 'lugar ampliado' já surge desde a sua criação. Portanto, Passos lida com essas questões de fragmentação desde o início, e os seus habitantes lidam com habilidade e normalidade com o que seria, na visão de Harvey, uma situação de ruptura e instabilidade.

\section{CONCLUSÃO}

Para concluirmos esta pequena reflexão, falta relacionar, ainda que rapidamente, a movimentação, o tempo e o espaço dela derivados com a construção de identidades locais. Passemos, assim, à relação entre espaços geográficos e identidade, relação que deve ser desnaturalizada e questionada segundo alguns autores (Gupta 1992, Gupta \& Ferguson 1992, Malkki 1992). Estes autores e outros pretendem demonstrar como se foi construindo uma forte relação entre espaços geográficos e identidade através do desenvolvimento recente dos Estados-Nação, e oferecem relações alternativas, considerando a fragmentação do espaço defendida por Harvey. Feldman-Bianco (1992, 1994) demonstra bem uma dessas alternativas ao tratar do transnacionalismo português, explorando uma definição de nação que se imagina espalhada pelo mundo nos próprios imigrantes portugueses.

O 'lugar ampliado' é um outro exemplo de alternativas a essa relação entre espaço e identidade. A identidade 
um 'espaço fragmentado' ao redor de Estação Passos. Passos é onde estão passando seus cidadãos, o que envolve uma idéia de movimentação constante entre os vários lugares - ao contrário da relativa rigidez da movimentação que se dá entre os membros 'espalhados' de comunidades de imigrantes e suas metrópoles, no caso do transnacionalismo (Schiller et alli 1992), onde se dá uma separação radical de espaço). Ser passense é estar em movimento pelos seus lugares espalhados e a própria vila.

Desse modo, espero ter demonstrado que, para entender as atuais disputas políticas em Passos é preciso recorrer à movimentação, que pode ser vista como precursora de uma série de 'sugestões' para a performance de um 'modo de vida' específico, construído ao longo do tempo. Vimos que essa movimentação local é baseada na experiência de um 'lugar ampliado', que significa se movimentar por um circuito que extrapola os próprio limites, mas que acaba por fazer parte de Passos. Vimos como essa movimentação passa a ser a 'fornecedora' de capital cultural, a vivência, base da construção da dominação de uns poucos sobre o distrito. Esse processo se acentuou principalmente na década de oitenta, após a morte de Carlos Ribeiro de Lino, o coronel local, juntamente com a transformação das características econômicas do distrito, que de produtor de café passou a ser uma 'comunidadedormitório'.

Devo ressaltar que o discurso de exclusão é construído a partir da experiência dessa movimentação, decisiva para entendermos a organização da vida política local, a formação de grupos de interesse e a participação de certos indivíduos nesse cenário político. Assim, demonstrei que para se entenderem as relações políticas locais, torna-se necessário partir da análise dessa característica de intensa movimentação local. Vimos também que é necessário entendê-la a partir do contexto histórico, compreendendo como se formou a partir da criação do distrito (em função da estação de trem). No desenvolvimento dessas idéias esbocei rapidamente como tempo e espaço são influenciados pela movimentação, provocando o que chamei de ritualização de uma experiência fragmentada dos mesmos. Por fim, indiquei como essas características são também a base da (re)construção de identidades locais.

Igor José de Renó Machado é doutorando em Ciências Sociais (IFCH-UNICAMP) e pesquisador do CEMI (C entro deEstudos de Migrações Internacionais). 


\section{NOTAS}

1 Os nomes Passos e Itareno são fictícios, a fim de preservar as localidades e pessoas (todas com nomes alterados) onde foi realizada a pesquisa.

2 O distrito conta com cerca de 500 habitantes e situa-se a seis quilômetros da sede do município do qual faz parte.

3 A análise é baseada nos quatro meses de trabalho de campo realizado em 1997, mais uma série de viagens e rápidas estadas durante a execução do trabalho. Além disso, como parte da estratégia de pesquisa, 35 histórias de vida foram feitas neste período. Num universo de cerca de 500 pessoas, este número de entrevistas representa cerca de $7 \%$ da população do bairro.

4 Cf. Caniello (1990), Cintra (1979), Lanna (1995), Carvalho (1968-69), Nunes Leal (1976), Pereira de Queiroz (1975).

5 Para o desenvolvimento dessas idéias, ver Machado (1997).

6 Os nomes dos atores reais desta história também foram trocados.

7 Sobre história e economia em Minas Gerais, cf. Wirth (1982), Hagopian (1986), Arruda (1990), Dulci (1984), Diniz (1986) e Moura (1978).

8 É uma espécie de transmigração interna. Schiller et al. (1992) cunham o conceito para explicar a relação entre migrantes (no caso internacionais) e o país de origem, que permanece intensa e constantemente renovada. No caso deste artigo, podemos considerar a movimentação regional como uma "transmigração interna".

9 Aqui os termos foram inventados.

10 Para um detalhamento destas disputas, ver Machado (1997).

11 Mas é preciso, ainda, qualificar quais são exatamente as noções de tempo para essas pessoas. O fato é que lidam com vários ritmos de tempo diferentes, de acordo com a movimentação que executam no lugar ampliado: passam os dias altemando os tempos rígidos das cidades vizinhas (como o horário da aulas, do emprego), os tempos do comércio em geral (mercados, lojas), o próprio tempo 'morto' dos deslocamentos espaciais (incluindo o tempo de espera dos meios de transporte como Kombis fretadas, o horário e atraso dos ônibus) e o tempo das diversões noturnas nessas cidades (principalmente sexta e sábado para os jovens). E lidam também com o ritmo natural das colheitas e da natureza (o tempo cíclico), e o tempo 'natural' de um pequeno distrito aos finais de semana, quando as pessoas sentam-se à sombra das árvores na praça para jogar conversa fora, como se diz. Ainda vivenciam um tempo desencaixado (Giddens 1991) da televisão. Assim, é fácil ver que a percepção de tempo está definitivamente ligada aos percursos espaciais executados pelas pessoas, alguns acentuando determinados ritmos temporais, outros acentuando outros. Temos uma percepção de tempo 'multifacetada', relacionada diretamente com os vários espaços por que passam as pessoas.

12 O nome do distrito, Estação Passos, deriva da estação com o mesmo nome. 


\section{REFERÊNCIAS BIBLIOGRÁFICAS}

ARRUDA, Maria A. do Nascimento. 1990. Mitologia da Mineiridade. São Paulo: Brasiliense.

BRANDÃO, Carlos R. 1993. "Parentes e Parceiros”. In: A. A. ARANTES et al., Colcha de Retalhos. 2ªed. Campinas: Editora da Unicamp.

DINIZ, Clélio Campolina. 1986. "O Paradoxo Mineiro: Fortalecimento Econômico e Enfraquecimento Político". III Seminário de Economia Mineira. Belo Horizonte: CEDEPLAR/Face/UFMG,

BOURDIEU, Pierre. 1977. Outline of a Theory of Practice. Cambridge: Cambridge University Press. . 1983. "Gostos de classe e estilos de vida”. In: Renato Ortiz (org.), Pierre Bourdieu. São Paulo: Ática. 1989.0 poder Simbólico. Lisboa: Difel.

CANIELLO, Márcio. 1990. “Patronagem e Rivalidade”. RBCS no14. São Paulo: Anpocs.

CARVALHO, J osé Murilo de. 1968-69. “Estudos de Poder Local no Brasil”. Revista Brasileira de Estudos Políticos 25/26 (julho/janeiro).

CINTRA, Carlos Otávio. 1979. "Tradicional Brazilian Politcs: An Interpretation of Relations Between Center and Periphery". In: Neuma Aguiar (ed.), The Structure of Brazilian Development. New Brunswick: Transaction Books.

DULCl, Otavio Soares. 1984. As Elites Mineiras e a Concialiação: a Mineiridade como Ideologia. Ciências Sociais Hoje. São Paulo: Cortez.

FELDMAN-BIANCO, Bela. 1992. “Multiple Layers of Time and Space: the Construction of Class, Ethnicity, and Nationalism among Portuguese Immigrants". In: G. Shiller, L. Basch \& C. Blanc-Szanton (orgs.), Towards a Transnational Perspective on Migration: Race, Class, Ethnicity, and Nationalism Reconsidered. New York: Annals of the New York Academy of Sciences, 645.

. 1994. "The state, saudade and the dialetics of deterritorialization and reterritorialization". Paper Wenner-Green Foundation for Anthropological Research: Mijas.

GIDDENS, A. 1991. As Consequências da Modernidade. São Paulo: Unesp.

GUPTA, Akhil. 1992. "The Song of the Nonaligned World: Transnational Identities and the Reinscription of Space in Late Capitalism". Cultural Anthropology vol 7, noำ.

GUPTA, Akhil \&J ames FERGUSON. 1992. “Beyond 'Culture': Space, Identity, and Politics of difference”. Cultural Anthropology vol 7, no1.

HAGOPIAN Frances. 1986. The Politics of Oligarchy: the Persistence of Tradicional Elites in Contemporary Brazil . Ph.D. Dissertation, Massachusetts Institute of Technology.

HARVEY, David. 1994. A Condição Pós-Moderna. São Paulo: Loyola.

LANNA, Marcos. 1995. A Dívida Divina: Troca e Compadrio no Nordeste Brasileiro. Campinas: Ed. Unicamp.

MACHADO, Igor J osé de Renó. 1997. Dias em Movimento: Espaço e poder numa comunidade-dormitório mineira. Dissertação de Mestrado em Antropologia, Unicamp. 
MALKI, Liisa. 1992. "National Geographic: the Rooting of Peoples and the Territorialization of National Identity Among Scholars and Refugies". Cultural Anthopology vol 7, no1.

MOURA, Margarida M. 1978. Os Herdeiros da Terra: Parentesco e Herança Numa Área Rural. São Paulo: Hucitec.

NUNES LEAL, V. 1976. Coronelismo, Enxada e Voto. São Paulo: Alfa e Ômega

PEREIRA de QUEIROZ, Maria Isaura. 1975. “O Coronelismo numa Interpretação Sociológica”. In: B. Fausto (org.), História Geral da Civilização Brasileira, vol. III. São Paulo: Difel.

SAHLINS, Marshall. 1990. Ilhas de História. Rio de J aneiro: J orge Zahar.

SCHILLER, Glick, L. Basch \&C. BLANC-SZANTON. 1992. “Transnationalism: A New Analytic Framework for Understanding Migration". In: G. Shiller, L. Basch \&C. Blanc-Szanton (orgs.), Towards a Transnacional Perspective on Migration: Race, Class, Ethnicity, and Nationalism Reconsidered. New York: Annals of the New York Academy of Sciences, 645.

SINGER, Paul. 1973. Migrações Internas: Considerações Teóricas Sobre seu Estudo. In: Migrações Internas e Desenvolvimento. Belo Horizonte: CEDEPLAR.

VAN VELSEN, J. 1987. "A análise situacional e o método de estudo de caso detalhado". In: Bela Feldman-Bianco (org.), Antropologia das Sociedades Contemporâneas. São Paulo: Global.

VINCENT, J oan. 1987. "A Sociedade Agrária como Fluxo Organizado: Processos de Desenvolvimento Passados e Presentes". In: Bela Feldman-Bianco (org.), Antropologia das Sociedades Contemporâneas. São Paulo: Global.

WIRTH, J ohn D. 1982. O Fiel da Balança: Minas Gerais na Federação Brasileira. Rio de J aneiro: Paz e Terra. 
RESUMO

Este artigo trata de um discurso de exclusão construído a partir da experiência da movimentação num distrito de uma pequena cidade mineira. A movimentação é decisiva para entendermos a organização da vida política local, a formação de grupos de interesse e a participação de certos indivíduos nesse cenário político. Procurarei esboçar rapidamente como tempo e espaço são influenciados pela movimentação, provocando o que chamei de ritualização de uma experiência fragmentada dos mesmos. Por fim, tento demonstrar como essas características são também a base da (re)construção de identidades locais.

\section{ABSTRACT}

This article is about exclusion's discourse produced from the experience of people's movement in a small town of Minas Gerais, Brasil. People's movement throughout the region is decisive to understand the organization of local political life, the formation of groups that share common interests and the participation of some individuals in this political scene. I will outline how this movement influences time and space, causing a "ritualization" of a fragmented experience. I also demonstrate how these characteristics are a foundation of the (re)construction of local identities. 